\title{
Izquierda peronista como cultura política (1955-1973)
}

\author{
Valeria A. Caruso
}

Instituto Ravignani, UBA / CONICET

caruso.valeria@gmail.com

Title: Peronist left as a political culture (1955-1973)

Resumen: Este trabajo analiza el proceso formativo de la izquierda peronista como cultura política durante el período de la proscripción del peronismo (19551973). En primer lugar, examina las doxas interpretativas que predominan en los trabajos historiográficos que abordan las relaciones entre intelectuales y política durante las décadas del 60 y 70 . En segundo término, revisa someramente las trayectorias e intervenciones de distintos referentes intelectuales peronistas que incidieron en el proceso de gestación de una cultura política en el interior del movimiento proscripto, atravesada por el tamiz teórico del marxismo.

Palabras claves: izquierda peronista - cultura política - proscripción al peronismo - intelectuales.

Abstract: This paper analyzes the formative process of the peronist left as a political culture during the period of the proscription of peronism (1955-1973). In the first place, it examines the interpretative doxas that predominate in the historiographical works that address the relations between intellectuals and politics during the decades of the 60 s and 70 s. Secondly, it briefly reviews the trajectories and interventions of different peronist intellectual referents that influenced the process of gestation of a political culture within the proscribed movement crossed by the theoretical sieve of Marxism.

Key words: left Peronism - political culture - proscription of peronism - intellectuals

Recepción: 24 de julio de 2019. Aceptación: 10 de agosto de 2019 .

(Archivos, año VIII, $\mathrm{n}^{\circ} 15$, septiembre de 2019, pp. 77-98) 


\section{Puntos de partida}

El golpe de Estado perpetrado por las Fuerzas Armadas en septiembre de 1955 hizo estallar el sistema de representaciones politicas por entonces vigente. El peronismo fuera del poder del Estado inició un proceso de reformulación política forzado por la expulsión, persecución e inhibición "legal" de sus referentes, de sus organizaciones y de su simbología. La continuidad de la proscripción y la clausura de los canales formales de la democracia liberal para el peronismo, junto con la persistente adhesión popular al gobierno depuesto, abrieron un umbral de discusión acerca de las comprensiones y saberes del fenómeno e inauguró un denso proceso de reformulación de idearios y prácticas políticas que signó de diferente manera a distintas tradiciones políticas por casi veinte años.

En este trabajo propongo analizar la crisis mencionada y sus efectos en el interior del peronismo. Es decir, observar cómo paulatinamente en el devenir de ese proceso político, y en relación con la coyuntura internacional, se articularon nuevas prácticas, discursos y representaciones sobre el peronismo que posibilitaron la emergencia de la izquierda peronista (IP) como una cultura política. Tomo como referencia los postulados de Jean François Sirinelli al advertir que

una cultura política es un conjunto de representaciones que cohesionan a un grupo humano en el plano político, es decir una visión del mundo compartida, una lectura común del pasado, una proyección hacia el futuro, vivida en grupo. Esto desemboca, dentro del combate político cotidiano, en la aspiración a tal o cual forma de régimen político y de organización socioeconómica, al mismo tiempo que sobre normas, creencias y valores compartidos. (Sirinelli, 1999: 462)

Una mirada atenta a las instancias formativas de la izquierda peronista (IP) permite evaluar una serie de elementos que están presentes desde sus comienzos, y que fueron resignificados por distintos actores retrospectivamente, interpelados por la necesidad de intervenir en la coyuntura politica local para transformarla. Fue bajo esa égida que se gestaron prácticas, símbolos e ideas que dieron forma a un peronismo de nuevo tipo, cimentando una activa comunidad de sentido que nutrió los contenidos y las formas de la IP como cultura política a lo largo de dieciocho años. Lo cual no quiere decir que esta cultura política que comienza su proceso formativo apenas unos años después de la proscripción al peronismo fuera homogénea y cerrada. Por el contrario, el análisis de los casos que se desarrollan en el segundo apartado de este 
trabajo muestra la mutación de ciertos tópicos e ideologemas de la tradición peronista resultantes del fragor de las luchas que ciertos actores mantuvieron con otros, dentro y fuera del heterogéneo Movimiento peronista, para sostener sus posiciones respecto al peronismo como vector de la transformación de la sociedad argentina.

Al respecto, vale recordar el planteo que realiza Serge Berstein en relación con el momento de surgimiento de las culturas políticas. E1 autor ha sugerido que su emergencia está asociada a grandes traumatismos políticos que "en la medida en que cuestionan las identidades, provocaron efectivamente la mutación, el abandono de culturas politicas sólidamente instaladas o la adhesión a nuevas formas de culturas políticas" (Berstein, 1999: 402). Es decir, una cultura política emerge como un "conjunto de representaciones de carácter normativo" en un contexto de crisis politica en el que se busca generar opciones con vistas a recomponer o transformar el orden político en un momento determinado. Asimismo, advierte su carácter evolutivo y relacional con otras culturas politicas, dado que una cultura política no puede transformarse "si no es chocando de frente con las tradiciones de las cuales obtiene precisamente una parte importante de su fuerza” (Berstein, 1999: 400). Otro aspecto señalado por el autor refiere a la doble dimensión de toda cultura politica, en tanto "es al mismo tiempo un fenómeno individual, interiorizado por el ser humano, y un fenómeno colectivo compartido por grupos numerosos" (Berstein, 1999: 401).

Es en ese intersticio, entre lo individual y lo colectivo, que resulta relevante recuperar la trayectoria de personalidades politicas, intelectuales y sindicales en el primigenio entramado de la IP como cultura politica. Es decir, el intento recurrente de dotar de significaciones a las ideas, iniciativas y acciones llevadas adelante por un sector del Movimiento peronista que intentó -en el trascurrir de los dieciocho años de la proscripción- direccionarlo en pos de la construcción del peronismo como una doctrina de liberación nacional. De allí la necesidad de recurrir a referencias desde las cuales fundamentar/legitimar prácticas, discursos y representaciones sobre los significados del peronismo en un contexto interpelado por la incidencia de la Revolución Cubana, las luchas de liberación nacional del Tercer Mundo y el despliegue de la hegemonía estadounidense a escala planetaria.

Al respecto, Guillermina Georgieff ha advertido que

la persistencia del peronismo como fenómeno político, la revolución cubana y los movimientos de liberación nacional fueron elementos primordiales en el horizonte político-ideológico de aquellos años, y sus presencias exigieron nuevas matrices para pensar la nación y reconsiderar la relación entre las 
izquierdas. [...] En ese contexto histórico cualquier narrativa no era posible y la "delimitación del rango de interpretaciones aceptables" estuvo dada por dichos procesos que obligaron a pensar el problema de la nación en referencia a un eje "nacional-popular". (Georgieff, 2016: 282) ${ }^{1}$

En ese marco, resulta relevante explorar el proceso formativo de la IP como cultura política, y poner en suspenso algunos aspectos que predominan en los abordajes historiográficos sobre las décadas del 60 y 70. En particular, me referiré a cinco cuestiones.

La primera de ellas se vincula con los resultados de distintos trabajos sobre las formaciones políticas identificables con la IP. Estudios como los de Claudia Hilb y Daniel Lutzky (1984), Maria Matilde Ollier (1986, 1989) y Hugo Vezzetti $(2002,2009)$, centrados en desentrañar las causas del "fenómeno insurreccional" en la Argentina, terminan generando -implícita o explícitamente- distintas genealogías que tienden a diagramar una suerte de "teleología de la violencia" subyacente a los fines politicos de estas organizaciones. Estas interpretaciones predominan en estudios recientes destinados a analizar las características culturales y politicas de los grupos que se identificaron con el peronismo entre fines de la década del 60 y principios de los 70 , como se advierte en los trabajos de Sebastián Carassai (2013), Daniela Slipak (2015), Moira Cristá (2016) y Mónica Bartolucci (2018), entre otros. No obstante, considero que ampliar la lente para observar los procesos formativos de las comunidades de sentido que se estructuraron por entonces permite matizar los juicios sobre la "primacía de la violencia revolucionaria" de los fines políticos, y apreciar no sólo la porosidad de esas experiencias, sino también alejarnos de la preminencia del paradigma "violentológico" tan presente en los trabajos sobre los 60 y 70 (Acha, 2012).

En segundo lugar, matizar la incidencia de la clausura del proceso de "modernización" cultural como clave interpretativa del proceso de politización de los intelectuales que se identificaron con la IP, presente en los ensayos de Silvia Sigal (1991) y Oscar Terán (1991). Estos autores plantean que, tras el derrocamiento de Perón en 1955, se inició un proceso de modernización científico y cultural que posibilitó la edificación del campo intelectual (Bourdieu, 2002). Este proceso, cancelado por el golpe de Estado de 1966, clausuró las posibilidades de proseguir con los programas de actualización cultural e intelectual, excluyendo a los intelectuales de los ámbitos de legitimación de sus prácticas espe-

1. En ese sentido, llama la atención la recurrente omisión de la Izquierda Peronista dentro de la "nueva izquierda" argentina emergente en los primeros años de la década del 60. Al respecto véase el trabajo de Sergio Friedemann (2018). 
cificas (Sigal, 1991). En este contexto político se habrian generado las condiciones para que un amplio sector de la intelectualidad argentina abandonara las concepciones del intelectual comprometido (Sartre, 1981) y adoptara la posición del intelectual revolucionario. Ese pasaje habría implicado la entrega a la acción política en detrimento de sus prácticas profesionales específicas. La influencia de la Revolución Cubana y de las luchas de liberación nacional, actuaron en la opción de la lucha armada como estrategia para superar la situación creada por el "bloqueo tradicionalista" instaurado por la autodenominada "Revolución Argentina" en junio de 1966 (Terán, 1991, 2008).

Estos ensayos han alumbrado una serie de investigaciones referidas a las características y modalidades de la participación de los intelectuales en el ámbito político durante el período. En esa línea de análisis se inscriben los trabajos de José de Diego (2000) y Claudia Gilman (2003) acerca de la politización de las letras latinoamericanas, los de Ana Longoni y Mariano Mestman $(1999,2008)$ y Ana Longoni (2014), en los que examinan las vinculaciones de los artistas plásticos de vanguardia con distintos colectivos políticos vinculados a la izquierda peronista, los concernientes al grupo Cine Liberación (Mestman, 1993, 2008), así como los dedicados a la indagación sobre la adhesión de los universitarios al peronismo (Barletta, 2000, 2002; Barletta y Lenci, 2000; Bartolucci, 2006).

Los trabajos antes mencionados, cuyas contribuciones son notorias, parten del supuesto de que la clausura del proceso de modernización cultural determinó las transformaciones intelectuales que se dieron en la Argentina entre 1955 y 1973. Incluso su influencia se observa en recientes investigaciones destinadas al análisis de los sectores medios (Carassai, 2013) y de las juventudes (Manzano, 2010, 2017). Sin embargo, las implicancias de la utilización de dicho supuesto como clave explicativa impide observar las características de la participación de los intelectuales en la conformación de las premisas prácticas, ideológicas y conceptuales que nutrieron el bagaje político e ideológico de la izquierda peronista.

El paradigma del intelectual de izquierda vigente en la Argentina durante las décadas del 60 y principios del 70 obligaba a la toma de posición respecto de las expectativas de transformación política y social vigentes por entonces. La existencia de este paradigma no inhibió las posibilidades de creación artística y de indagación intelectual. Más bien se orientó a una paulatina reconfiguración de las incumbencias intelectuales en estrecha vinculación con las expectativas de cambio radical existentes en el periodo. ${ }^{2}$

2. El establecimiento de normas y pautas de validación científica en el ámbito de las 
Por lo cual resulta pertinente recuperar la noción elaborada por Bauman (1995) del "intelectual" como intérprete de la cultura, en tanto su función social es la de generar una comunidad de significados. Lo cual posibilita una aproximación a la dimensión contingente y contextual de las prácticas intelectuales, en tanto éstas no pueden ser comprendidas acabadamente a través de la teoría de campo intelectual elaborada por Bourdieu. Las acciones e iniciativas realizadas por los referentes de la IP durante el período dificilmente puedan reducirse a sus ambiciones de validación intelectual en los términos planteados por el sociólogo francés. Resulta más apropiado como herramienta de análisis el concepto de "productores culturales" acuñado por Raymond Williams (1994), dado que posibilita examinar las acciones de aquellos agentes intervinientes en procesos de elaboración, circulación y reapropiación cultural. Una aproximación de esta índole permitirá observar las motivaciones y transformaciones que condujeron a un sector de la intelectualidad argentina a identificarse y actuar en la izquierda peronista desde los comienzos de la proscripción del peronismo.

En tercer lugar, dejar en suspenso los juicios sobre las causas de la "derrota" del paradigma revolucionario en pos de acceder a las dimensiones estructurantes de sentido que signaron las ideas y las acciones que llevaron adelante hombres y mujeres en la gesta de un proyecto político del cual conocemos su resultado. Al respecto, resulta pertinente recuperar los planteos teórico-metodológicos elaborados por Quentin Skinner (2007) en lo que respecta a la comprensión de los discursos políticos en su contexto de producción histórica. Su enfoque permite reconstruir las prácticas significativas, los usos e intenciones de las "ideas", eludiendo la imposición de modelos puramente externos. Realizar esta operación, habilita considerar a la IP en la contingencia de su devenir en tanto tal, y observarla como una cultura politica en gestación permanente, aunque estructurada en torno a ciertos principios políticos e ideológicos que se irán condensando y rearticulando en el desarrollo de una coyuntura politica situada. Es decir, apreciar tanto su dimensión contingente como la heterogeneidad de una cultura política porosa y conflictiva, signada por las desavenencias de su vértice político que siempre es Perón. Pero aun cuando éste desautorice, denueste o expulse a sus huestes, éstas persistirán en su adhesión al líder exiliado, elaborando diversas prácticas y narrativas que permitirán la cohesión de distintos grupos políticos en el entendimiento de que sin peronismo no hay revolución social posible en la Argentina. Y es en el plano del "rechazo", de la exclusión o de la desautorización en donde, en

ciencias sociales y las humanidades escindidas de objetivos políticos explícitos recién se consolida en nuestro país en 1984. 
distintas ocasiones, se ponen en escena iniciativas creativas para seguir concibiendo al peronismo como una doctrina de liberación nacional.

Una cuarta cuestión a tener en cuenta refiere a la dificultad historiográfica para considerar a los peronistas como intelectuales, más aún a los que se presentaban en sociedad como "peronistas y marxistas". 3 Considero que esa dificultad se explica, en parte, por la persistencia de identificar a la izquierda peronista dentro de la órbita de la izquierda nacional, homologando ambas identificaciones, cuando los referentes de cada una de esas tradiciones, si bien podían compartir ámbitos de sociabilidad politica e intelectual, perseguian y militaban proyecciones políticas bastante disimiles. ${ }^{4}$ Lo cual no implica negar contactos y lineas de convergencias de distintos referentes de la IP con militantes de las izquierdas disidentes desde mediados de los 50, estudiados por Herrera (2016), Tortti (2009), Rot (2016) y Mangiantini (2018), entre otros, sino intentar cubrir una vacancia historiográfica en relación a cómo repensó el peronismo un sector de ese hemisferio durante la proscripción.

Lo cual nos introduce a una quinta cuestión, que refiere a la habitualidad historiográfica de pensar la permanencia de la identidad peronista en esos años en términos de "estructura de sentimiento" dando por sentado un ser y estar en el peronismo que la evidencia empírica muestra problemática y conflictiva. La utilización de una categoría analítica como un insumo descriptivo ha conllevado a dar como dada la identidad peronista durante los primeros años de la proscripción. Abordajes de este tipo obturan la posibilidad de interrogarnos acerca de cómo la crisis política iniciada en 1955, prolongada durante dieciocho años, intervino en la reconfiguración identitaria de un sector del heterogéneo movimiento.

No obstante, es preciso señalar que se ha configurado un campo específico de estudios sobre la izquierda peronista. El trabajo pionero de Germán Gil (1989) examinó la evolución del significante peronismo situándolo en su contexto de emergencia y evaluando las múltiples determinaciones que lo atravesaron en su conformación ideológica. Richard Gillespie (2008), Lucas Lanusse (2010) y Julieta Bartoletti (2011) han explorado el proceso formativo de la organización armada Montoneros; Esteban Campos (2016) y Daniela Slipak (2015) han analizado la

3. Una cuestión similar ha planteado Guillermo Korn (2018) para el período 19451955.

4. Esas divergencias fueron públicas en los debates de la época como, por ejemplo, los que se presentan en el semanario El popular, en el que Hernández Arregui rechazaba cualquier tipo de homologación con los juicios políticos e históricos realizados por Jorge Abelardo Ramos. Véase Hernández Arregui, "Doble enfoque sobre la izquierda nacional", El popular, n¹0, 17 de noviembre de 1960, p. 10. 
configuración identitaria de esta organización a través de sus órganos de prensa. Los trabajos de Daniel James (1990), Juan Bozza (2001) y Marcelo Raimundo (2001) reconstruyen el contexto histórico en el que se reelaboraron las prácticas políticas de la izquierda peronista. Sin embargo, carecemos de un abordaje de historia intelectual que permita acceder a las transformaciones ideológicas y conceptuales que produjo un sector del peronismo durante la proscripción.

De allí que convenga explicitar la especificidad de la izquierda peronista y examinar su proceso formativo prestando especial atención al contexto de emergencia y desarrollo de una forma de entender el peronismo, distinta al periodo 1945-1955. La disputa por los sentidos y las formas que debía adoptar el peronismo estuvo signada por la prohibición legal de su existencia. Desde entonces, se dinamizaron distintas estrategias de visibilidad y cohesión política no sólo para dirimir rivalidades hacia el interior del movimiento, sino también para movilizar adhesiones, presentar alternativas políticas que, incluso, pudieron ser disimiles a los planes de Perón en el ejercicio de un liderazgo remoto, amenazado permanentemente por la dispersión de sus referentes y la dilución de su dominio sobre la conducción local.

Durante los dieciocho años que duró la proscripción emergieron formas de "ser" y actuar en el peronismo condicionadas por un contexto continuamente trasformado por los avatares de la coyuntura politica local e internacional. Esto incidió en la paulatina configuración de la izquierda peronista como cultura política, atravesada por la necesidad de distintos actores por gestionar y mantener adhesiones para sus proyecciones políticas. En su interior se gestaron símbolos e ideas tendientes a legitimar nuevos espacios de poder dentro del movimiento. Esto no implicó la "virtualidad" de la izquierda peronista, sino que, por el contrario, fue intrínseco a su devenir activo y militante en relación con una nueva comprensión del fenómeno, que fue mutando en función de las necesidades de los actores por sostener sus posiciones y proyecciones sobre la fuerza politica proscripta.

En ese sentido, las disputas por la vigencia del peronismo, pero sobre todo por el ejercicio del poder al interior del movimiento, no se iniciaron en 1966 o en 1973, sino que atravesaron toda su historia. Las pujas por el poder de mando en el interior del movimiento se potenciaron con la finalización abrupta del gobierno de Perón. Estas disputas no sólo expresaron distintas estrategias políticas, sino también tensiones por quién ostentaba mayor capital simbólico y político para conducir las cuerdas del heterogéneo movimiento. Tales fricciones expresaban la situación de tensión permanente entre distintos liderazgos que incidieron en el proceso formativo de la izquierda peronista como cultura política.

En el trascurrir de los dieciocho años, esas tensiones se manifestaron 
de distinta manera potenciando, por momentos, determinados liderazgos en detrimento de otros. En ese juego de tensiones, los actores emprendieron distintas acciones para mantener su vigencia politica, e incluso intentar construir alternativas de poder cuando los canales tradicionales o instituidos para imponer sus posiciones estuvieron vedados.

Al estudiar los textos de Cooke (Caruso, 2017), Eguren (Caruso, en prensa) y Hernández Arregui (Caruso, 2019a), puede advertirse que la introducción del lenguaje marxista no solo tenía una función ideológica, sino también práctica y "posicional" respecto a otros peronistas y a las distintas formaciones de izquierda que, luego de 1955 , pero sobre todo luego de la "traición de Frondizi", disputaban con el peronismo la representación de los sectores populares que persistian en su adhesión al movimiento proscripto. Es decir, la introducción del marxismo en el peronismo no sólo se debió a su vinculación con referentes de las izquierdas, sino que fue también tramitada por intelectuales peronistas en función de su necesidad de intervenir en las discusiones politicas de la época para reafirmar el carácter revolucionario del peronismo y sus posiciones, dentro y fuera del Movimiento. Justamente, como el peronismo fue concebido por los peronistas como una fuerza revolucionaria desde su emergencia en la escena pública, durante los primeros años de la proscripción comenzó a tramarse una discursividad política que fue condensando, a lo largo de dieciocho años, una promesa de transformación económica social revolucionaria que, a su vez, actuaba como umbral de diferenciación respecto de otros sectores del peronismo y de las izquierdas.

En ese contexto, distintos actores desarrollaron prácticas e ideas que le dieron sentido a un conjunto de prescripciones politicas que diferenciaran a la IP de otras izquierdas. En primer lugar, el reconocimiento de la soberanía política del peronismo sobre cualquier otro proyecto de transformación político-social. Los usos del marxismo tramados desde la IP son del orden de la praxis contra la "derecha burocratizada" del Movimiento. Su verdad reside en reexaminar la gesta del lider exiliado a través de distintas herramientas teórico-conceptuales provenientes del legado marxista que permitieron la reformulación del peronismo como una doctrina de la liberación nacional anticapitalista.

Las convergencias y líneas de fuga de esa comunidad de sentido pueden advertirse no sólo en distintas publicaciones y emprendimientos de la IP, sino también en las prácticas e ideas que desarrollaron distintos actores interpelados por el "núcleo duro" de significaciones y principios que le dieron sentido a esa cultura politica. Nos referimos a un conjunto de prescripciones politicas que diferenciaran a la IP de otras izquierdas. ${ }^{5}$

5. En particular, con la denominada izquierda nacional de los 60. Es habitual en- 
Asimismo, es necesario aclarar una cuestión más en relación con la noción de IP. Si bien la denominación "Peronismo Revolucionario" fue utilizada por distintos actores durante el periodo que aborda este trabajo, la misma no da cuenta de la magnitud de las mutaciones ideológicas, políticas y discursivas que se dieron en el interior del peronismo en las décadas del 60 y 70 . Más aún si observamos que esta fuerza política se consideraba a sí misma revolucionaria desde el mismo momento de su emergencia, y que incluso durante las décadas que aborda esta indagación los sectores más ortodoxos del movimiento ensalzaban el carácter revolucionario del peronismo (Besoky, 2016). Para estos últimos, la gesta por hacer era la de forjar las condiciones para el retorno de Perón al poder, y así continuar con la transformación peronista interrumpida por el golpe de Estado de septiembre de 1955. Sin embargo, desde ese momento, comenzaron a estructurarse nuevas formas de entender el contenido revolucionario del peronismo en función de la realización de un socialismo nacional sólo edificable desde el seno del Movimiento proscripto, sin que ello conllevara a la reedición de las iniciativas del primer peronismo.

Al respecto, es preciso considerar que entre 1955 y 1973 distintos referentes intelectuales -aunque no únicamente ellos-incidieron en la elaboración de distintas prácticas, ideas y símbolos que posibilitaron concebir al peronismo como una doctrina de liberación nacional anticapitalista. De alli que sólo algunos años después de la Revolución Cubana, de manera heterogénea, comience a formularse la noción de izquierda peronista como categoria nativa (Acha, Campos, Caruso y Vigo, 2017). Esta concepción discute con una narrativa "nativa" (de la ortodoxia o derecha peronista) acerca de la IP como formación política no obrera, de clase media o intelectual-universitaria, porque si bien esos elementos de clase están presentes en su formación, se desarrollaron en interacciones de clase múltiples en las que los sindicatos y activistas obreros no estuvieron ausentes.

Los intelectuales, junto con otros sectores del movimiento peronista, formularon los principios políticos e ideológicos que nutrieron y guiaron el accionar del ala izquierda del peronismo como respuesta a la proscripción en 1955. Durante dieciocho años, los integrantes de la izquierda

contrar en la bibliografia referida a las izquierdas de los 60 y 70 la homologación de las interpretaciones de Jorge Abelardo Ramos con las de Cooke, a quienes algunos autores los emparentan dentro de la Izquierda Nacional. Sin embargo, un análisis exhaustivo de sus propuestas políticas pone en evidencia los disensos que los separan. Los referentes de la izquierda nacional se conciben a sí mismos siempre desde el exterior del peronismo, al que conciben como una experiencia de nacionalización de la clase obrera en lucha contra el imperialismo alienante desde la primacía teórica del marxismo. 
peronista examinaron los problemas internos del movimiento peronista que posibilitaron el derrocamiento de Perón y la continuidad de la prohibición de esta fuerza política. Los diagnósticos sobre las limitaciones y disputas internas del peronismo, junto con las condiciones politicas impuestas por los gobiernos democráticos y de facto que gobernaron la Argentina durante el período, condujeron a la reelaboración de una cultura política peronista a través de la adopción de premisas ideológico-politicas marxistas (en algunos casos no sin dosis de crítica), con el fin de crear las condiciones que posibilitaran el retorno al poder del líder depuesto y, con él, lograr la consumación de la "revolución nacional" anticapitalista.

\section{Puntos de llegada}

En relación con lo anterior, resulta significativo el recorrido político e intelectual transitado por John William Cooke. Desde su actividad parlamentaria durante el primer peronismo, su rol en la comandancia del peronismo local en el período inicial de la proscripción y las discrepancias con Perón acerca del rumbo que debía de adoptar el movimiento prohibido, se advierte la intención de fundamentar su posición siempre en tensión con otros liderazgos. En esos contextos críticos Cooke tramó nuevos entendimientos para concebir al peronismo como un movimiento de liberación nacional. La experiencia cubana, de la cual fue testigo y participante, no sólo le brindó un marco para pensar nuevas maneras de intervención política a través de la lucha armada, sino también novedosos andamiajes discursivos para evaluar las causas que habian determinado el fin de la experiencia peronista en el poder del Estado. La imposibilidad de reeditar la alianza democrático-burguesa del período 1945-1955 ponía en evidencia las limitaciones de esa estrategia para enfrentar los peligros que significaban el capital monopólico en el país. La defensa de la nación y de las clases populares, por la que pugnaba el peronismo, sólo podría imponerse a través de la lucha insurreccional que erradicara las formas capitalistas de producción.

Desde la perspectiva de Cooke, la identificación de las burocracias politicas y sindicales que actuaban en el interior del Movimiento habian provocado el fin del gobierno de Perón. De allí que demandara una actualización doctrinaria, que purgara a las conducciones claudicantes y que evitara el desfasaje del peronismo respecto de los problemas que afectaban a la sociedad argentina durante la década del 60. Esa reformulación doctrinaria por la que clamaba el ex delegado de Perón no debía realizarse en cualquier dirección, sino que debía orientarse en el marco de los postulados teóricos del marxismo. La obra de Marx señalaba que "el capital" y sus reglas dominan por completo cualquier 
entendimiento sobre los destinos de las naciones. Dicho entendimiento deviene de la advertencia acerca de la potencialidad revolucionaria del peronismo en tanto encarnación de la nación y del sentir del pueblo oprimido. Su defensa y su triunfo demandaba una definición ideológica y estratégica como movimiento de liberación nacional anticapitalista. Esto, a su vez, significaba una potencial amenaza para el orden que se expresaba en la continuidad de la proscripción. Las prohibiciones que recaían sobre el peronismo y un Estado cada vez más violento con aquellas fracciones del peronismo y del movimiento obrero que resistían los intentos de integración al sistema político-institucional daban cuenta de la potencial amenaza que significaban las fuerzas populares. La toma del poder en términos revolucionarios sólo se podría efectuar a través del peronismo proscripto, única fuerza política con capacidad de movilizar y conducir a las masas. El déficit del movimiento estaba en sus conducciones, por lo cual también era preciso formar cuadros revolucionarios que desplazaran a las dirigencias burocráticas para emprender el camino insurreccional.

Si bien la actuación política de Cooke hacía el interior del peronismo fue marginal durante este período, su legado intelectual nutrió los derroteros políticos de nuevas camadas de militantes peronistas. Su esfuerzo teórico y político no se redujo al ámbito del peronismo, sino que intentó interpelar a otros actores. Particularmente, a aquellos que se autopercibian revolucionarios y defensores de los intereses nacionales, para advertirles que el peronismo era el vehículo a través del cual se expresaba el pueblo en su lucha por la liberación.

En ese sentido, la empresa historiográfica iniciada por Juan José Hernández Arregui, continuada por Rodolfo Ortega Peña y Eduardo Luis Duhalde, forjó una renarración de la historia efectiva al brindar una lectura del pasado nacional que resituaba al peronismo como continuidad histórica de la expresión política de las gestas populares. Asimismo, Hernández Arregui habilitó un contexto que permitió otorgarle inteligibilidad a su manera de entender el peronismo: "Soy peronista porque soy marxista", decía a principios de los años $60,{ }^{6}$ y en ese decir, inauguró una formulación que creció en visibilidad y contundencia en el transcurso de los dieciocho años en los que el peronismo estuvo proscripto. La difusión de estas premisas a lo largo de la década del 60 se observó en las colaboraciones realizadas en distintas revistas políticas de la época, en las polémicas que entablaron con distintos referentes de la historiografia revisionista, pero también en los emprendimientos editoriales autogestivos que llevaron adelante con el objeto de dar a conocer

6. Hernández Arregui, "Doble enfoque sobre la izquierda nacional", El popular, $\mathrm{n}^{\circ} 10$, 17 de noviembre de 1960 , p. 10 
su reinterpretación del pasado nacional. Crearon, junto a otros actores, un espacio para su realización intelectual a través de la relectura que realizaron del peronismo y de la historia nacional.

En esa línea se destacan los semanarios 18 de marzo y Compañero de Mario Valotta. ${ }^{7}$ En estas publicaciones se fue construyendo una "peronicidad" particular en un contexto político marcado no sólo por las prohibiciones vigentes para el peronismo, ${ }^{8}$ sino también por las disputas internas que atravesó el movimiento en el contexto de reorganización partidaria ordenado por Perón en $1963 .{ }^{9}$ En esa coyuntura, se difundieron de marcas de autoridad, simbolos y referencias tendientes a afirmar una forma específica de comprender la pertenencia al peronismo, ponderando a las bases peronistas como sujeto de la liberación nacional por hacer. Esta concepción se basaba en la potencialidad transformadora de los trabajadores y trabajadoras argentinos que habian creado el peronismo. Dentro de este entendimiento, resultaba imprescindible que fuera esclarecida su centralidad en el proceso revolucionario. La exhortación permanente a la "rebelión de las bases", estructurada ideológicamente en torno al decálogo obrero de Huerta Grande, precisaba de conducciones adecuadas para la toma del poder. La confianza que, en un primer momento, estos semanarios depositaron en el liderazgo de Framini comenzó a ser cuestionado luego de que su proceder fuera considerado zigzagueante ante el aumento de la injerencia del vandorismo en los órganos de conducción del peronismo local. En ese contexto, los cuadros intermedios del sindicalismo combativo, sobre todo los del interior del país, fueron ponderados como potenciales impulsores de las tendencias revolucionarias que anidaban en el peronismo. ${ }^{10}$

Asimismo, la lectura de Compañero posibilita observar las manifestaciones de descontento de los y las militantes "de a pie" frente a los liderazgos peronistas locales. La publicación de cartas de lectores en las que eran evaluados los resultados del proceso eleccionario de 1963 y el proceder de los referentes politicos del Movimiento dio visibilidad a voces

7. Estas publicaciones, dirigidas por Mario Valotta entre 1962 y 1964, alcanzaron tiradas superiores a los 30.000 ejemplares por número. Además, contaba con un grupo de prestigiosos colaboradores como Rogelio García Lupo, Pedro Barraza, Julio Notta, Álvaro Abós, German Rozenmacher, Ricardo Carpani, Juan José Hernández Arregui, Rodolfo Ortega Peña y Eduardo Luis Duhalde, entre otros.

8. Por peronicidad nos referimos a las maneras situadas en las que los actores desplegaron enunciados para probar su condición de peronistas. Lo cual requería que estos fueran "interpretables, comprensibles, inteligibles para otros actores dedicados ellos también a producir de manera exitosa su condición de peronistas" (Garzón Rogé, 2017).

9. Sobre la relevancia del proceso de reorganización partidaria véase Smulovitz (1988). 10. Un análisis pormenorizado de estas publicaciones se encuentra en Caruso (2019b). 
que pensaron al peronismo como una fuerza de liberación política y social que no podía ser contenida dentro de la institucionalidad burguesa.

El análisis de la trayectoria sindical y política de Raimundo Ongaro permite recuperar la dimensión intelectual de este referente de la izquierda peronista, y problematizar las relaciones entre intelectuales y clase obrera. Éstas, habitualmente, han sido tematizadas o abordadas desde una posición en la que se pondera la intención de los "intelectuales" comprendidos desde la exterioridad del mundo del trabajo y de la clase obrera, de influenciar el accionar de los trabajadores en torno a proyecciones politicas que le son ajenas. En general, las tesis sobre el "entrismo" que intelectuales y políticos radicalizados realizaron durante los 60 y 70, además de concluir sobre la inoperatividad de esta práctica, terminan enfatizando -implícitamente- la pasividad de los y las trabajadores y su imposibilidad para pensar alternativas al orden de cosas imperante. Con esto no se busca poner en discusión el "entrismo" en sí, ni negar esa práctica. Interesa poner en cuestión el carácter pasivo de los trabajadores y las trabajadoras para resignificar sus propias vivencias.

De allí que la exploración de la actuación política, pero, sobre todo, intelectual, de Ongaro habilite nuevas perspectivas para analizar la gravitación de este referente del sindicalismo combativo. Más sí tenemos en cuenta que ya en sus primeros escritos públicos presentó una reflexión sobre la explotación laboral y sus perjuicios para el bienestar obrero. El sindicato fue su espacio de aprendizaje y de reflexión. La preocupación por mejorar la vida de sus representados fue un primer incentivo para ganar la conducción de la Federación Gráfica Bonaerense, desde la cual fomentó la representación de base como modalidad antitética de las prácticas burocratizantes predominantes en el sindicalismo local. En marzo de 1968 esa prédica pareció ampliarse -desde el gremio hacia el conjunto de la sociedad-, a través de la CGT de los Argentinos (CGTA), impulsando la iniciativa de articular la "rebelión de las bases" en un frente civil de resistencia contra la opresión política y económica que impuso con violencia la dictadura de Onganía.

La clausura de la CGTA no impidió que la prédica de Ongaro continuara proyectándose sobre la sociedad argentina. No solamente en el plano político -estrechamente vinculado al peronismo de base-, sino también filosófico. Sus reflexiones sobre la explotación del sistema capitalista, sus alternativas y el rol que les correspondia a los y las trabajadoras en las luchas por hacer, abrieron un umbral de cognición en el que las bases obreras estaban en el centro de la escena como actores y promotores de su propia liberación. ${ }^{11}$

La incidencia de Ongaro en el empoderamiento de las bases obreras,

11. He desarrollado esta cuestión en Caruso (2019c). 
además de reposicionar el accionar politico de los sindicatos en las gestas de la época, colaboró en la cristalización de una nueva forma de concebir el peronismo como una fuerza politica anticapitalista más allá del ámbito sindical. También intentó influir y confluir con otros actores en un ámbito donde la izquierda peronista fue pensada y actuada como una doctrina de liberación. Sobre este último entendimiento Ongaro tuvo un lugar capilar, no sólo como tenaz disertante y difusor de nuevas formas de entender la actividad gremial, sino también como referente político e intelectual de las trabajadoras y trabajadores contra la opresión capitalista.

Otra referente fundamental de la izquierda peronista ha sido Alicia Eguren. El estudio de su devenir militante pone de manifiesto las dificultades que atravesó para construir su propio capital político en el interior del peronismo durante el período de la proscripción. Sus intentos por incidir en la resistencia peronista y en la reorganización de la rama femenina, a contrapelo de los lineamientos sostenidos por sus dirigentes tradicionales, se vieron mitigados por la autoridad de Perón. Las desavenencias de las luchas políticas en el interior del movimiento proscripto y, posteriormente, su activa participación en la experiencia cubana nutrieron sus expectativas de transformación social a través del movimiento peronista. ${ }^{12}$

Luego de su retorno a la Argentina en 1964 organizó junto a Cooke la agrupación Acción Revolucionaria Peronista, un espacio de militancia que sostuvo incluso ante el desencanto de la promesa que albergaba el retorno de Perón. Eguren se percibía a sí misma como la "madre" de la opción revolucionaria de nuevas camadas militantes. A raíz de ese alumbramiento, y de una tenaz lucha por su vigencia -que incluyó la organización y publicación de la correspondencia Perón-Cooke-, reclamó para sí un lugar de poder en el heterogéneo movimiento. Sus expectativas sobre el peronismo en el poder se fueron licuando en la medida en que el "mito" -como llamaba a Perón- parecía haberse escindido de sus bases, alejado de su pueblo y de todos y todas aquellas que, como ella, habian luchado de distintas maneras por la promesa que albergaba el regreso del general al país. Esos dias felices, los de la expectativa, se volvian amargos en la medida en que "el Líder" se negaba a recibirla para escuchar las alternativas revolucionarias que Eguren había pergeñado a lo largo de dieciocho años. El despliegue de credenciales militantes

12. Alicia Eguren, "La revolución nacional cubana y la Argentina", El popular, n ${ }^{\circ}$ 9, Buenos Aires, 10 de noviembre de 1960, pp. 14-15. Un estudio exhaustivo de la trayectoria político-intelectual de Eguren durante el período de la proscripción al peronismo se encuentra en Caruso (en prensa). 
pareció insuficiente ante el vacío que dejaba la ausencia de los gestos anhelados de Perón.

A principios de las décadas del 70, la noción de "socialismo nacional" resultaba nodal para muchos peronistas. No sólo para aquellos que integraban organizaciones armadas. Esta cuestión se advierte en las transcripciones de un ciclo de mesas redondas en las que sindicalistas combativos, referentes intelectuales y politicos de la izquierda peronista se reunieron para discutir en qué consistía el socialismo para el peronismo. Estas "Mesas redondas sobre socialismo nacional" se llevaron a cabo durante el mes de septiembre de $1972 .{ }^{13}$ La relevancia de este documento no sólo radica en que contiene un conjunto de pareceres que habitualmente no han sido suficientemente tenidos en cuenta en los trabajos sobre el período, sino que, además, estas intervenciones estuvieron condicionadas por la particularidad de un contexto politico signado por la cercanía temporal con la masacre de Trelew y la crisis terminal que atravesaba la autodenominada "Revolución Argentina".

En el marco de estas disertaciones se vertieron distintos pareceres acerca de las confluencias y desencuentros entre marxismo y peronismo. Las posiciones de distintas personalidades -de extracciones disimiles tanto profesionales como territoriales- respecto del peronismo como vehículo del socialismo nacional da cuenta de un entendimiento com-

13. "Mesas redondas sobre el socialismo nacional", Buenos Aires, CIPLEN, septiembre de 1972, Archivo Carpani, IIPC-Tarea, Unsam. El ciclo fue organizado por los "Centros Iberoamericanos para la Liberación Nacional" (CIPLEN), una institución coordinada por Carlos Oscar Suárez y Juan José Hernández Arregui. Su realización se llevó a cabo en tres encuentros desarrollados en las sedes de tres sindicatos vinculados al sindicalismo combativo como la Federación Gráfica Bonaerense (FGB), el sindicato de empleados de Farmacia y el de telefónicos de la Capital Federal. En el primero de ellos, disertaron Carlos Suárez del Frente Peronista Octubre, Osvaldo Villaflor por la FGB, Luis Tossi, como representante del Ateneo de Estudios Sociales, y Mario L. Aguirre, secretario general de ATE Rosario. El segundo encuentro contó con la participación de Juan Carlos Gené en representación de la Asociación Argentina de Actores; Roberto Digón, secretario general de la Asociación de Empleados del Tabaco seccional Capital; Jorge Di Pascuale, secretario general de la Asociación de Empleados de Farmacia (ADEF); Roberto Páez, por la Agrupación "Revolución Peronista"; Leandro Fote, dirigente gremial de la FOTIA (Federación Obrera de los Trabajadores de la Industria del Azúcar) Tucumán, y Jorge Cerletti, del periódico Hacia el Socialismo Nacional. En la última mesa participaron Juan José Hernández Arregui; Julio Guillán, secretario general de FOETRA; Luis Cerruti Costa, abogado laboralista y defensor de presos políticos; Ricardo Carpani, artista plástico, muralista y ensayista de temas politicos; Benito Romano, dirigente de la Coordinadora de ingenios cerrados de Tucumán, y directivo de la FOTIA en distintos períodos; Alfredo Carballeda, dirigente de la Agrupación "Lealtad y Soberanía del Peronismo Revolucionario"; y Tomás Saraví, representante de la "Agrupación de Periodistas Peronistas 26 de Enero". Un análisis pormenorizado de estas discusiones se encuentra en Caruso (2019a). 
partido respecto de la centralidad del movimiento proscripto en la trasformación política y social del país. Cada uno de los expositores vinculó su experiencia militante con sus entendimientos sobre el socialismo y el peronismo, a la vez que desplegaron diversas síntesis interpretativas que condensaban nuevas conexiones entre dos postulados políticos que dos décadas atrás parecían no sólo irreconciliables, sino también antagónicas. Ese viejo antagonismo fue puesto en discusión en cada uno de estos encuentros e, incluso, llegó a preguntarse por qué los obreros argentinos reivindicaban al peronismo y no al marxismo como estandarte de liberación.

Los esfuerzos de los participantes en estas mesas de discusión estuvieron dirigidos a develar la amalgama de sentidos que contenía la izquierda peronista en su anhelo por el "socialismo nacional". En esas intervenciones primó la necesidad de diferenciarse de las "burocracias" políticas y sindicales que transgredian sistemáticamente el contenido emancipador del Movimiento proscripto, pero también, de fundamentar sus propias aspiraciones de construcción de un poder popular que eliminara la explotación capitalista. Consideraban que los trabajadores argentinos en sus luchas por la vigencia del peronismo habian afirmado su percepción acerca de que, sin la erradicación de las normativas jurídicas e institucionales sobre las cuales el capitalismo sustentaba su reproducción, no podría lograrse la definitiva emancipación nacional que anhelaban.

Por otro lado, estas discusiones permitieron advertir cómo en el seno del movimiento fue reconsiderada la vigencia del peronismo como una fuerza de liberación nacional anticapitalista. Las experiencias militantes vivenciadas durante los dieciocho años de proscripción, junto con las limitaciones de la coyuntura política argentina y la existencia de un paradigma revolucionario para los países del Tercer Mundo, alimentaron las expectativas de transformación política y social que el peronismo debía realizar. Lo cual pone en tensión aquellas tesis que sostienen la "virtualidad" de la izquierda peronista en relación con la "materialidad" de las decisiones de Perón, que a su vez, evidenciaría el equívoco de concebir al peronismo como una expresión política de izquierda. Esas perspectivas pierden de vista las reelaboraciones creativas que distintos actores realizaron en su devenir militante durante los dieciocho años de la proscripción. Durante esas casi dos décadas, distintos referentes politicos e intelectuales crearon distintas maneras de entender el peronismo para fundamentar sus intenciones de transformación política y social en el país. 


\section{Reflexiones finales}

Desde mediados de los años 50, en el interior del peronismo se tramaron nuevas claves de intelección para la recuperación del poder del Estado que incidió no sólo en las ideas, sino también en las prácticas desarrolladas por los referentes de la IP en pos de la consecución de sus anhelos de trasformación politica, económica y cultural. En el transcurrir de la proscripción, las experiencias intelectuales aquí estudiadas evidencian aportes de distinta índole que delinearon los márgenes de la izquierda peronista como cultura política. Es decir, recuperando una vez más los postulados de Sirinelli, "un conjunto de representaciones que cohesionan a un grupo humano en el plano político" en su entendimiento de que el peronismo expresaba los anhelos de liberación nacional de las mayorias oprimidas. Para su realización debía repensarse su doctrina a través del prisma del marxismo, no como entelequia teórica sino como expresión de las luchas que los y las peronistas vivenciaron durante los dieciocho años de proscripción. Además, la adopción de este lenguaje permitió reafirmar los balances sobe la derrota del 55 y diferenciar a las burocracias politicas y sindicales que transgredian el contenido emancipador y popular del peronismo.

La categoría de "productores culturales" resultó pertinente para reconsiderar las contribuciones de los referentes políticos e intelectuales analizados en la medida en que, cada uno de ellos, colaboró en la reelaboración del legado peronista como una fuerza de liberación nacional anticapitalista. Esa directriz se advierte desde los primeros años de la proscripción como un esfuerzo por diferenciar posiciones en el interior del movimiento y a la vez crear espacios de legitimidad política. Aunque su incidencia concreta en los espacios de decisión política del peronismo fue marginal, la influencia de sus ideas respecto a los cauces que debía adoptar el movimiento como fuerza de emancipación anticapitalista nutrió los imaginarios políticos de la época.

Durante la década de 1960 se articuló una profunda renovación simbólica del peronismo que dificilmente pueda ser comprendida dentro de los lineamientos de un "bloqueo tradicionalista" a un proceso de modernización cultural o a las necesidades insatisfechas de reconocimiento intelectual. Por el contrario, fueron las tensiones y disputas de la coyuntura política de la época las que delinearon los márgenes y los nudos argumentativos que posibilitaron la paulatina articulación de la IP como cultura política. Hacia fines de esa década ya existía un corpus de representaciones disponibles para expresar no solo una diversidad de experiencias, sino también de intelecciones para fundamentar la existencia de un peronismo atravesado por el tamiz teórico del marxismo.

Por otro lado, dejar de lado las premisas del paradigma "violentológi- 
co" posibilitó apreciar la emergencia de diversas instancias de intervención política no reducibles a la primacía de la violencia revolucionaria. Las proyecciones que desarrollaron los actores analizados en este trabajo deben ser contempladas en el marco de la temporalidad que contienen los conceptos políticos en la modernidad. Los horizontes de expectativa que abrieron tanto el peronismo en el período de la proscripción como la revolución cubana alumbraron perspectivas de futuro en el que la liberación nacional parecía realizable.

Todo proyecto por hacer se mide en función de sus condiciones de posibilidad en el presente en el que se desarrollan. Ese futuro que habitamos ha juzgado esos convencimientos pasados como equivocados, errados, velados, autoengañados en relación con unas expectativas de presente que no fueron las de los actores que estudiamos ¿Cómo hacer para comprender, en vez de juzgar aquello acontecido? La única respuesta a ese interrogante es la de tratar de entender, antes que enjuiciar, los anhelos de los hombres y mujeres del pasado por materializar sus ideas. Estas no han trascurrido en soledad en el llano de la historia. Contuvieron un conjunto de rugosidades, contingencias y novedades que condicionaron sus opciones en el complicado e inestable devenir de sus propias elecciones.

\section{Bibliografía}

Acha, Omar (2009), Historia critica de la historiografia argentina. Las izquierdas en el siglo XX, Buenos Aires: Prometeo.

- (2012), Un revisionismo histórico de izquierda: y otros ensayos de politica intelectual, Buenos Aires: Herramienta.

Acha, Omar, Esteban Campos, Valeria Caruso y Mariano Vigo (2017), "Izquierda peronista: una categoria útil para el análisis histórico", Historiografias, revista de historia y teoria, $\mathrm{n}^{\circ} 17$, Zaragoza: Universidad de Zaragoza.

Barletta, Ana María y Laura Lenci (2000), "Politización de las ciencias sociales en Argentina. Incidencia de la revista Antropología Tercer Mundo", Sociohistórica: Cuadernos CISH, $\mathrm{n}^{\circ} 8$.

Barletta, Ana (2000), "Universidad y política: la "peronización" de los universitarios (1966-1973)", Pensamiento Universitario, n 9, UNQui.

- (2002), "Una izquierda peronista universitaria. Entre la demanda académica y la demanda política, 1968-1973”, Prismas, Revista de historia intelectual, $\mathrm{n}^{\circ} 6$.

Bartoletti, Julieta (2011), Montoneros: de la movilización a la organización, Rosario: Laborde Libros.

Bartolucci, Mónica (2006), "Juventud rebelde y peronistas con camisa. El clima cultural de una nueva generación durante el gobierno de Onganía", Estudios Sociales, año 16. 
- (2018), La juventud maravillosa. La peronización y los orígenes de la violencia politica, 1958-1972, Buenos Aires: Eduntref.

Bauman, Zygmunt (1995), Legisladores e intérpretes, Buenos Aires: UNQui.

Berstein, Serge (1999), "La cultura política", en Jean-Pierre Rioux y JeanFrançois Sirinelli, Para una historia cultural, México: Taurus.

Besoky, Juan Luis (2016), La derecha peronista. Prácticas politicas y representaciones (1943-1976), tesis de doctorado: Universidad Nacional de La Plata.

Bourdieu, Pierre (2002), "Campo intelectual y proyecto creador", Campo de poder, campo intelectual. Itinerario de un concepto, Buenos Aires: Montressor.

Bozza, Juan (2001), "El peronismo revolucionario. Itinerario y vertientes de la radicalización, 1959-1969", Sociohistórica, n 9-10.

Campos, Esteban (2016), Cristianismo y revolución. El origen de Montoneros, Buenos Aires: Edhasa.

Carassai, Sebastián (2013), Los años setenta de la gente común. La naturalización de la violencia, Buenos Aires: Siglo XXI.

Caruso, Valeria (2017), "La forja de la izquierda peronista como cultura política a través de la trayectoria de John W. Cooke”, Páginas, revista digital de la Escuela de Historia.

- (2019a), "Intelectuales e izquierda peronista: sus relaciones con la universidad y el movimiento obrero. 1955-1973", tesis de doctorado, FFyL-UBA.

- (2019b), "Derivas de la izquierda peronista a través de las lecturas de 18 de marzo y Compañero", Avances del Cesor (en prensa).

- (2019c), "Raimundo Ongaro, un intelectual para la liberación de las bases", Claves. Revista de Historia, vol. 5, n 8, Facultad de Humanidades y Ciencias de la Educación, Universidad de la República.

- (en prensa), "Del nacionalismo a los cauces de la izquierda peronista: Un recorrido posible por la trayectoria politica e intelectual de Alicia Eguren durante el periodo de proscripción del peronismo", Izquierdas.

Cristá, Moira (2016), Imaginaire péroniste. Esthétique d'un discours politique (1966-1976), Rennes: Presses Universitaires de Rennes.

De Diego, José (2000), ¿Quién de nosotros escribirá el Facundo? Intelectuales y escritores en Argentina (1970-1986), La Plata: Al Margen.

Friedemann, Sergio (2018), "La izquierda peronista de los años 60 como fenómeno argentino de la nueva izquierda", Tempo e Argumento, vol. $20, n^{\circ} 24$.

Garzón Rogé, Mariana (2017), "Un espécimen peronista. Pruebas de identidad y modos prácticos de ser en el primer peronismo", Pilquen, vol. $20, n^{\circ} 4$.

Gil, Germán (1989), La izquierda peronista (1955-1974), Buenos Aires: CEAL.

Gillespie, Richard (2008), Soldados de Perón. Historia crítica sobre los Montoneros, Buenos Aires: Sudamericana.

Gilman, Claudia (2003), Entre la pluma y el fusil. Debates y dilemas del escritor revolucionario en América Latina, Buenos Aires: Siglo XXI. 
Georgieff, Guillermina (2016), Nación y revolución: Itinerarios de una controversia en Argentina 1960-1970, Buenos Aires: Prometeo.

Herrera, Carlos (2016), ¿Adiós al proletariado? El Partido Socialista bajo el peronismo (1945-1955), Buenos Aires: Imago Mundi.

Hilb, Claudia y Daniel Lutzky (1984), La nueva izquierda en Argentina: 19601980. Politica y violencia, Buenos Aires: CEAL.

James, Daniel (1990), Resistencia e integración: el peronismo y la clase trabajadora argentina, 1946-1976, Buenos Aires: Sudamericana.

Korn, Guillermo (2018), Hijos del pueblo. Intelectuales peronistas: de la internacional a la marcha, Buenos Aires: Las Cuarenta.

Lanusse, Lucas (2010), Montoneros. El mito de sus doce fundadores, Buenos Aires: Zeta.

Longoni, Ana (2014), Vanguardia y revolución. Arte e izquierdas en la Argentina de los sesenta-setenta, Buenos Aires: Ariel.

Longoni, Ana y Mariano Mestman (1999), "Vanguardia y revolución. Acciones y definiciones por una "nueva estética", en Alfredo Pucciarelli (ed.), La primacía de la politica. Lanusse, Perón y la nueva Izquierda en tiempos del GAN, Buenos Aires: Eudeba.

- (2008), Del Di Tella a "Tucumán Arde". Vanguardia artística y politica en el 68 argentino, Buenos Aires: Eudeba.

Mangiantini, Martín (2018), Itinerarios militantes. Del Partido Revolucionario de los Trabajadores al Partido Socialista de los Trabajadores (1965-1976), Buenos Aires: Imago Mundi.

Manzano, Valeria (2010), "Juventud y modernización sociocultural en la argentina de los sesenta”, Desarrollo Económico, vol. 50, nº 199.

- (2017), La era de la juventud en Argentina. Cultura, politica y sexualidad desde Perón hasta Videla, Buenos Aires: Fondo de Cultura Económica.

Mestman, Mariano (1993), "Aproximaciones a una experiencia de cine militante (Argentina, 1968-1973)", en AA.VV., Arte y poder, V Jornadas de Teoría e Historia de las Artes, Buenos Aires, Centro Argentino de investigadores de las Artes, FFyL, UBA.

- (1997), "Semanario CGT. Rodolfo Walsh, periodismo y clase obrera", Causas y Azares, $\mathrm{n}^{\circ} 4$.

- (2008), "Raros e inéditos del Grupo Cine Liberación", Sociedad, n 27.

Ollier, María Matilde (1986), El fenómeno insurreccional y la cultura politica (1969-1973), Buenos Aires: CEAL.

- (1989), Orden, poder y violencia, Buenos Aires: CEAL.

Raimundo, Marcelo (2001), "Compañero y los orígenes del Peronismo Revolucionario", Sociohistórica, $\mathrm{n}^{\circ} 8$, Universidad Nacional de La Plata.

Rot, Gabriel (2016), Itinerarios revolucionarios. Eduardo L. Duhalde - Haroldo Logiurato. De la resistencia peronista al partido revolucionario de los obreros argentinos, Buenos Aires: De la Campana.

Sartre, Jean-Paul (1981), ¿Qué es la literatura?, Buenos Aires: Losada.

Sigal, Silvia (2001), Intelectuales y poder en la década del sesenta, Buenos Aires: Siglo Veintiuno. 
Sirinelli, Jean-François (1999), "Las elites culturales”, en Jean-Pierre Rioux y Jean-François Sirinelli, Para una historia cultural, México: Taurus.

Skinner, Quentin (2000), "Significado y comprensión en la historia de las ideas politicas", Prismas: revista de historia intelectual, $\mathrm{n}^{\circ} 4$.

Slipak, Daniela (2015), Las revistas montoneras. Cómo la organización construyó su identidad a través de sus publicaciones, Buenos Aires: Siglo XXI.

Smulovitz, Catalina (1988), "Crónica de un final anunciado: las elecciones de marzo de 1962", Desarrollo Económico, vol. 28, n 109.

Terán, Oscar (1991), Nuestros años sesenta. La formación de la nueva izquierda intelectual argentina, Buenos Aires: Puntosur.

- (2008), Historia de las ideas en la Argentina. Diez lecciones iniciales, 18101980, Buenos Aires: Siglo Veintiuno.

Tortti, María Cristina (2009), El “viejo" partido socialista y los origenes de la "nueva" izquierda, Buenos Aires: Prometeo.

Vezzetti, Hugo (2002), Pasado y presente. Guerra, dictadura y sociedad en la Argentina, Buenos Aires: Siglo XXI.

- (2009), Sobre la violencia revolucionaria. Memorias y olvidos, Buenos Aires: Siglo XXI.

Williams, Raymond (1994), Sociología de la cultura, Barcelona: Paidós. 